\title{
Analysis on the Influencing Factors of Iron and Manganese Content in Shallow Groundwater in the Water Source-Area near the Feng River in Xi'an
}

\author{
Zhuoran Wang ${ }^{1}$, Xiaoguang Zhao ${ }^{1}$, Wenjie Nie ${ }^{1}$, and Huadong $\mathrm{Du}^{1}$ \\ ${ }^{1}$ Xi'an University of Science and Technology
}

September 4, 2020

\begin{abstract}
Iron and manganese ions, as the main contribution indicator of super-class III shallow groundwater in the western suburbs of Xi'an, seriously threaten the safety of local water supply and the health of residents. Based on data collection and hydrogeological survey, this paper studies the concentration of iron and manganese in groundwater by collecting and analyzing 52 groups of groundwater samples, and analyzes the possible sources of iron and manganese in consideration of human factors such as hydrogeological conditions and surface pollution input. The results showed: (1) The highest iron content exceeded the Class III water quality standard by 1.03 times, and the highest manganese content exceeded the Class III water quality standard by 3.92 times. The water sample points exceeding Class III accounted for $9.5 \%$ and $26.2 \%$ of the total water sample points respectively. (2) The content of iron and manganese in the water of Feng River is $8.47 \%$ and $19.69 \%$ of the groundwater respectively. Therefore, the higher iron and manganese in individual wells near the source of Feng River have no obvious relationship with Feng River. (3) According to drilling data, the iron and manganese content in different rock masses is silty clay $>$ round gravel $>$ fine sand, medium-coarse sand, and the distribution of iron and manganese content is positively correlated. (4) In the experiment of the iron and manganese release law in the rock mass, it was observed that the iron and manganese in the overlying water experienced three stages of rapid increase, fall and stabilization. When the final release stabilizes, the release rate of manganese in the rock mass is higher than that of iron. The manganese content in the overlying water is $0.010^{\sim} 0.057 \mathrm{mg} / \mathrm{L}$, the release rate is $0.02 \%^{\sim} 0.05 \%$, and the iron content is $0.004^{\sim} 0.023 \mathrm{mg} / \mathrm{L}$, the release rate is less than $0.01 \%$, and the higher $\mathrm{pH}$ in the water environment has a significantly higher inhibitory effect on the release of iron in the rock mass than manganese.
\end{abstract}

\section{Hosted file}

Title page.pdf available at https://authorea.com/users/356354/articles/479249-analysis-onthe-influencing-factors-of-iron-and-manganese-content-in-shallow-groundwater-in-thewater-source-area-near-the-feng-river-in-xi-an 
Analysis on the Influencing Factors of Iron and Manganese

Content in Shallow Groundwater in the Water Source-Area near the Feng River in Xi'an 
Keywords: Hydrogeochemistry; water pollution; $\mathrm{Fe}$ ion; $\mathrm{Mn}$ ion 
ABSTRACT: Iron and manganese ions, as the main contribution indicator of super-class III shallow groundwater in the western suburbs of Xi'an, seriously threaten the safety of local water supply and the health of residents. Based on data collection and hydrogeological survey, this paper studies the concentration of iron and manganese in groundwater by collecting and analyzing 52 groups of groundwater samples, and analyzes the possible sources of iron and manganese in consideration of human factors such as hydrogeological conditions and surface pollution input. The results showed: (1) The highest iron content exceeded the Class III water quality standard by 1.03 times, and the highest manganese content exceeded the Class III water quality standard by 3.92 times. The water sample points exceeding Class III accounted for $9.5 \%$ and $26.2 \%$ of the total water sample points respectively. (2) The content of iron and manganese in the water of Feng River is $8.47 \%$ and $19.69 \%$ of the groundwater respectively. Therefore, the higher iron and manganese in individual wells near the source of Feng River have no obvious relationship with Feng River. (3) According to drilling data, the iron and manganese content in different rock masses is silty clay $>$ round gravel $>$ fine sand, medium-coarse sand, and the distribution of iron and manganese content is positively correlated. (4) In the experiment of the iron and manganese release law in the rock mass, it was observed that the iron and manganese in the overlying water experienced three stages of rapid increase, fall and stabilization. When the final release stabilizes, the release rate of manganese in the rock mass is higher than that of iron. The manganese content in the overlying water is $0.010 \sim 0.057 \mathrm{mg} / \mathrm{L}$, the release rate is $0.02 \% \sim 0.05 \%$, and the iron content is $0.004 \sim 0.023 \mathrm{mg} / \mathrm{L}$, the release rate is less than $0.01 \%$, and the higher $\mathrm{pH}$ in the wate environment has a significantly higher inhibitory effect on the release of iron in the rock mass than manganese. 
ABSTRACT: Iron and manganese ions, as the main contribution indicator of super-class III shallow groundwater in the western suburbs of Xi'an, seriously threaten the safety of local water supply and the health of residents. Based on data collection and hydrogeological survey, this paper studies the concentration of iron and manganese in groundwater by collecting and analyzing 52 groups of groundwater samples, and analyzes the possible sources of iron and manganese in consideration of human factors such as hydrogeological conditions and surface pollution input. The results showed: (1) The highest iron content exceeded the Class III water quality standard by 1.03 times, and the highes manganese content exceeded the Class III water quality standard by 3.92 times. The water sample points exceeding Class III accounted for $9.5 \%$ and $26.2 \%$ of the total water sample points respectively. (2) The content of iron and manganese in the water of Feng River is $8.47 \%$ and $19.69 \%$ of the groundwater respectively. Therefore, the higher iron and manganese in individual wells near the source of Feng River have no obvious relationship with Feng River. (3) According to drilling data, the iron and manganese content in different rock masses is silty clay $>$ round gravel $>$ fine sand, medium-coarse sand, and the distribution of iron and manganese content is positively correlated. (4) In the experiment of the iron and manganese release law in the rock mass, it was observed that the iron and manganese in the overlying water experienced three stages of rapid increase, fall and stabilization. When the final release stabilizes, the release rate of manganese in the rock mass is higher than that of iron. The manganese content in the overlying water is $0.010 \sim 0.057 \mathrm{mg} / \mathrm{L}$, the release rate is $0.02 \% \sim 0.05 \%$, and the iron content is $0.004 \sim 0.023 \mathrm{mg} / \mathrm{L}$, the release rate is less than $0.01 \%$, and the higher $\mathrm{pH}$ in the water environment has a significantly higher inhibitory effect on the release of iron in the rock mass than manganese.

Keywords: Hydrogeochemistry; water pollution; $\mathrm{Fe}$ ion; $\mathrm{Mn}$ ion

1. INTRODUCTION

Water resources play an important role in promoting orderly economic development, ensuring the basic lives of urban and rura residents, and maintaining ecological balance. Surface water and groundwater are important components of water resources. Compared with surface water, groundwater is more widely distributed and requires less investment in mining and utilization. Especially in some arid nd semi-arid areas, surface water resources are relatively scarce, and the role of groundwater is particularly obvious. In the development an utilization of groundwater, the riverside groundwater source has sufficient water quantity and good water quality, so riverside mining ha become an important method of groundwater utilization.

In recent years, due to the intensification of human activities, the impact on groundwater is increasing and the dependence is increasing. While developing and utilizing groundwater

resources, we are facing one of the most serious problems-groundwater pollution. Groundwater pollution refers to the phenomenon that groundwater quality is deteriorating under the influence of human activities. In addition to the impact of human activities, the natural geological environment may also have inferior quality water ${ }^{1-5}$. In the evaluation of groundwater pollution, it is difficult to determine the background value or the control value due to the influence of human activities. It often includes groundwater pollution caused by some natural factors, which exaggerates the evaluation results and cannot correctly provide a scientific basis for proposing groundwater pollution prevention measures ${ }^{6-11}$. According to data, the quality of most of the shallow groundwater in Xi'an is mainly $\mathrm{Fe}, \mathrm{Mn}$, and ammonia nitrogen. Among them, $\mathrm{Fe}$ and $\mathrm{Mn}$ are listed as secondary pollutants in the "Secondary Drinking Wate Standards: Guidance for Nuisance Chemicals" issued by the US Environmental Protection 
REFERENCES

(1) Matisoff G, Khourey C J, Hall J F, et al. The nature and source of arsenic in north-western Ohio groundwater [J]. Ground Water, 1982, 20: 446-456.

(2) Varsányi I, Fodre Z, Bartha A. Arsenic in drinking water and mortality in the Southern Great Plain, Hungary[]]. Environmental Geochemistry and Health, 1991, 13: 14-22.

(3) Wyllie J. An investigation of the source of arsenic in well water [J]. Canadian Journal of Public Health, 1937, 28 : 128

(4) Wang L F, Liu H D, Xu X F, et al. Investigation Repor on Chronic Endemic Arsenic Poisoning in Kuitu Reclamation Area, Xinjiang []]. Chinese Journal of Endemiology, 1983, 2(2)

(5) Welch A H, Lico M S, Hughes J L. Arsenic in ground water of the western United States []]. Ground Water, 1988 26(3): $333-347$

(6) ZHANG Q, WANG H, WANG Y, et al. Groundwater quality assessment and pollution source apportionment in a intensely exploited region of northern China [J]. Environmental Science \& Pollution Research, 2017, 24(20) 16639-16650.

(7) ZHANG X W, HE J T, HE B N, et al. Assessment, formation mechanism, and different source contributions of dissolved salt pollution in the shallow groundwater of Hutuo River alluvial-pluvial fan in the North China Plain []] Environmental Science \& Pollution Research, 2019, 26(35): $35742-35756$

(8) Zhang X W, He J T, Huang G X. Distribution characteristics and cause analysis of iron and manganese in shallow groundwater in Shijiazhuang area [J]. Earth Science Frontiers, 2020, 7, 4: 1-14

(9) Ali M, Mohammad A M, Mohammad M M, et al. Environmental Hydrogeochemistry Characteristics, Controlling Factors and Groundwater Quality Assessment in Herat City, West Afghanistan[ []]. Hydrochemistry, Hydrobiology: Environmental Aspects, 2020, 47(2) 325-335.

(10) Barnes, N.A., Kehew, A.E., Krishnamurthy, R.V. al. Redox evolution in glacial drift aquifers: role o diamicton units in reduction of $\mathrm{Fe}(\mathrm{IIII})$. Environ Earth Sci 62, 1027-1038 (2011)

(11) Carretero, S., Kruse, E. Iron and manganese conten in groundwater on the northeastern coast of the Buenos Aire
Province, Argentina. Environ Earth Sci 73, 1983-1995 (2015)

(12) USEPA. Secondary Drinking Water Standards: Guidance for Nuisance Chemicals $[\mathrm{EB} / \mathrm{OL}]$ (2004)[2019-01-15],

https://www.epa.gov/sdwa/secondary-drinking-water-standar ds-guidance-nuisance-chemicals

(13) Daughney CJ (2003) Iron and manganese in New Zealand's groundwater. J Hydrol (NZ) 42(1):11-26

(14) Sally C.Homoncik, Alan M. MacDonald, Kate V. Heal, et al. Manganese concentrations in Scottis groundwater [J]. Science of the Total Environment, 2010, 5 , 12(408): 2467-2473.

(15) Merch N D, Auqu L F, Acero P, et al. Geochemical processes controlling water salinization in an irrigated basin in Spain: Identification of natural and anthropogenic influence [J]. Science of the Total Environment, 2015, 502 330-343.

(16) Guler C, Kurt M A, Alpaslan M, et al. Assessment of the impact of anthropogenic activities on the groundwater hydrology and chemistry in Tarsus coastal plain (Mersin, SE Turkey) using fuzzy clustering, multivariate statistics an GIS techniques []]. Journal of Hydrology, 2012, 414/415: 435-451.

(17) Re V, Sacchi E, Mas-pla J, et al. Identifying the effects of human pressure on groundwater quality to suppor water management strategies in coastal regions: multi-tracer and statistical approach (Bou-Areg region, Morocco)[]. Science of the Total Environment, 2014, 500/501: 211-23

(18) Luo Y L, Li J, Jiang P A, et al. Distribution, classification and cause analysis of geogenic high-arsenic groundwater in Kuitun, Xinjiang [J]. Acta Scientia Circumstantiae, 2017, 37(8): 2897-2903.

(19) Yuan W ZH. Biogeochemical process of $\mathrm{Fe}$ and $\mathrm{Mn}$ during river bank infiltration affected by groundwater exploiting [D]. Jilin University, 2017

(20) Hu X F, Lu H Y. Peculiarities in Soil-formin Processes of Paleosols in the Loess Plaeau AND Their Pedogenic Implication []]. Acta Pedologica Sinica, 2004(05): 669-675.

(21) Guo ZH T, Liu D SH, An ZH SH. Interglacial dustfall and the accretionary paleosols in loess. In: Gong Z T. ed. Environment Change of Soils (In Chinese). Beijing: Chinese 
Data Availability Statement

Research data are not shared. 

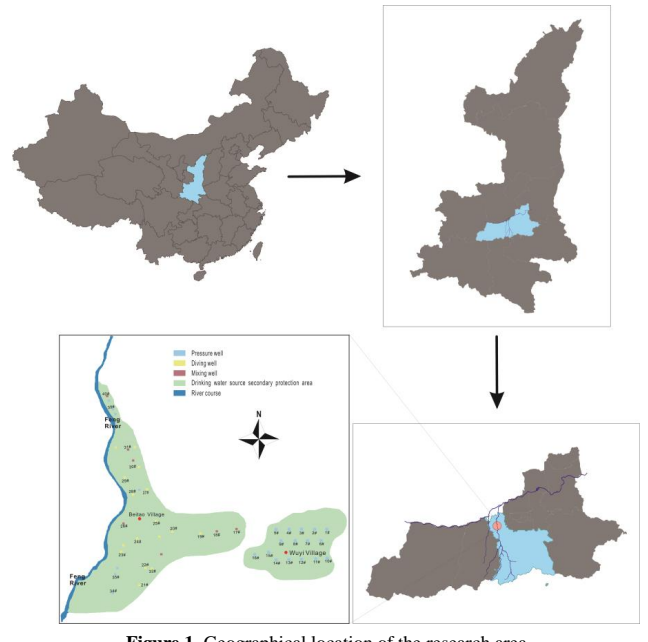

Figure 1. Geographical location of the research area

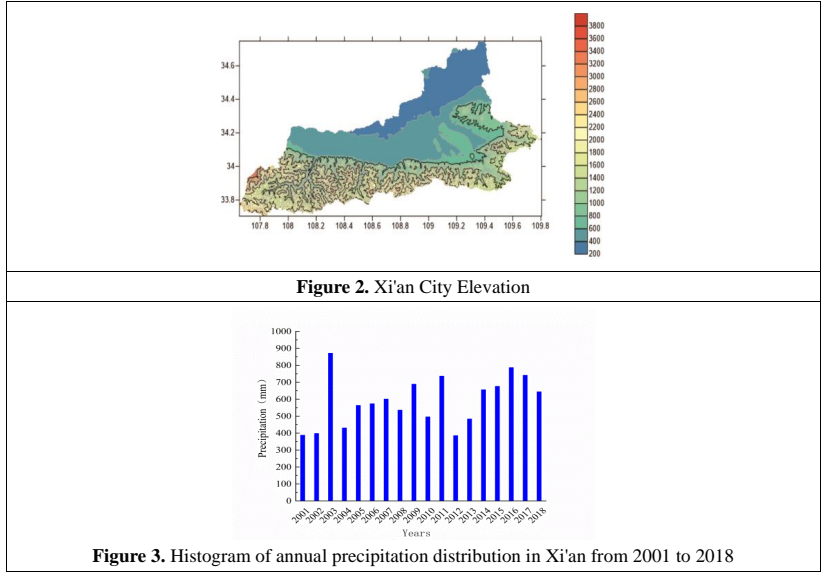

Figure 3. Histogram of annual precipitation distribution in Xi'an from 2001 to 2018 
Table 1. Formation lithology distribution statistics table

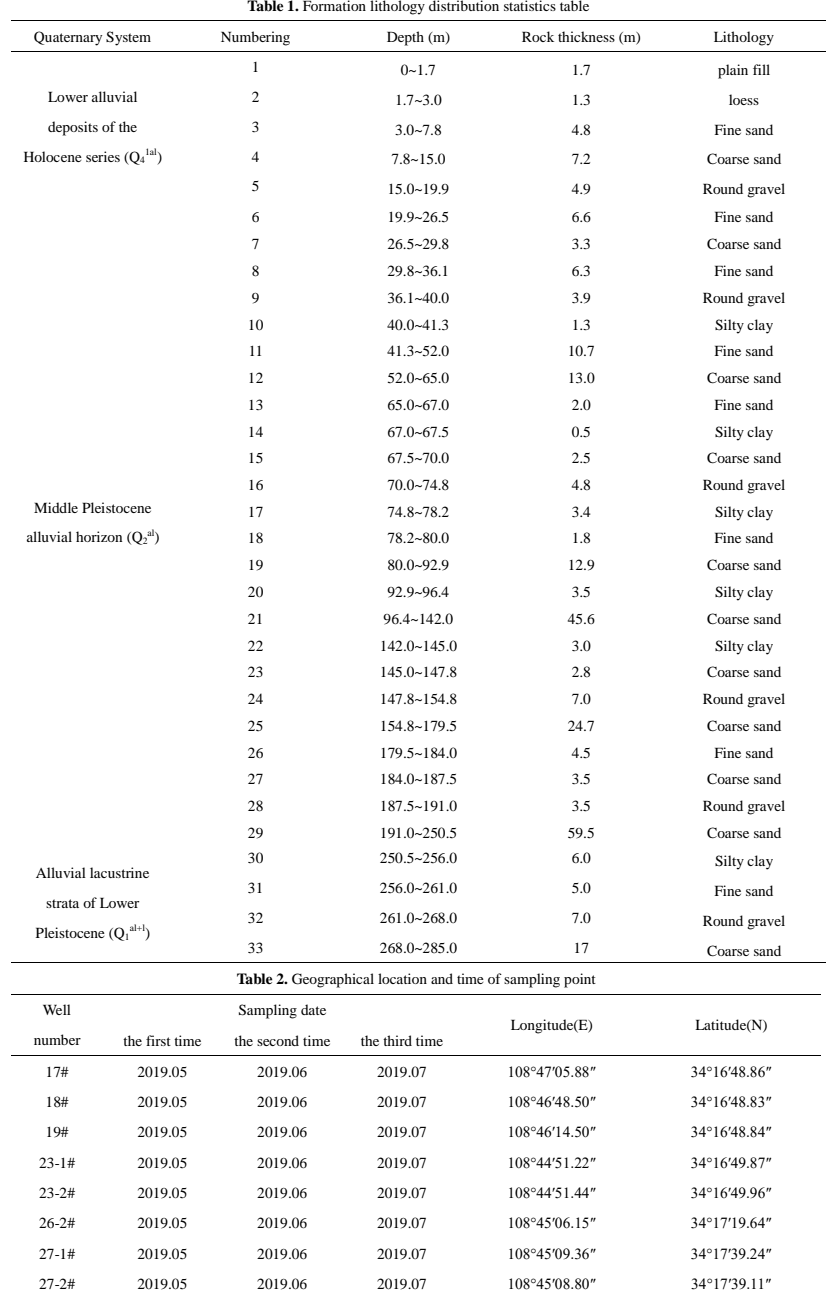




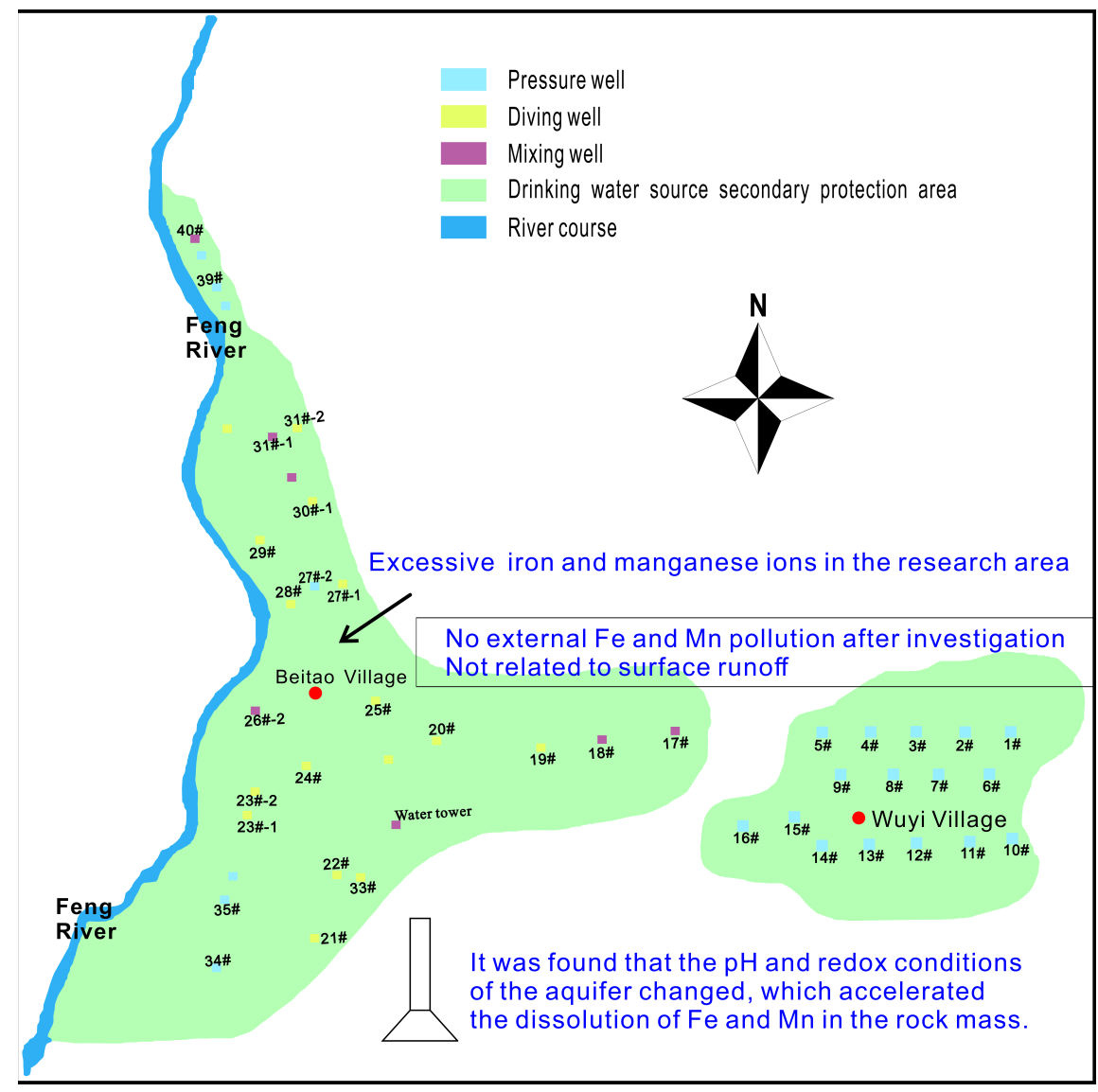

